\title{
Early-onset spastic ataxia-myoclonic epilepsy-neuropathy syndrome
}

INSERM

\section{Source}

INSERM. (1999). Orphanet: an online rare disease and orphan drug data base. Early-onset spastic ataxia-myoclonic epilepsy-neuropathy syndrome. ORPHA:313772

Early-onset spastic ataxia-myoclonic epilepsy-neuropathy syndrome is a rare hereditary spastic ataxia disorder characterized by childhood onset of slowly prog ressive lower limb spastic paraparesis and cerebellar ataxia (with dysarthria, swallowing difficulties, motor degeneration), associated with sensorimotor neuropathy (including muscle weakness and distal amyotrophy in lower extremities) and progressive myoclonic epilepsy. Ocular signs (ptosis, oculomotor apraxia), dysmetria, dysdiadochokinesia, dystonic movements and myoclonus may also be associated. 